\title{
Leveraged Guanxi in Employment Acquisition: Scale Development and Validation
}

\author{
Philip Rose ${ }^{1}$ \\ ${ }^{1}$ Department of Global Business, Hannam University, Daejeon, Korea \\ Correspondence: Philip Rose, Department of Global Business, Hannam Univerity, Daejeon, 70 Hannamro, \\ 306-791, Korea. Tel: 82-42-629-8507. E-mail: Dr.Philip.S.Rose@gmail.com
}

$\begin{array}{lc}\text { Received: September 19, } 2014 & \text { Accepted: January 18, } 2015 \quad \text { Online Published: April 20, } 2015 \\ \text { doi:10.5539/ass.v11n10p19 } & \text { URL: http://dx.doi.org/10.5539/ass.v11n10p19 }\end{array}$

\begin{abstract}
The Chinese organisational sphere is impacted upon by a number of relatively distinct contextual variables; prevalent amongst these variables, is the Chinese manifestation of social network ties, guanxi. Thus, in order to further advance our understanding of this influential Chinese phenomenon, the development of tailored measures of guanxi is required. Therefore, this paper develops and performs the validation of a new scale designed to measure a particular manifestation of guanxi. The new scale's items were generated and validated over four studies, consisting of focus group discussions, free-listing, pile-sorting and scenario activities $(n=126)$, followed by a pilot test $(n=227)$ and a test distribution of the scale $(n=506)$. The studies generated items representing both the categorical and dynamic dimensions of guanxi, as well the dimension of influence. The studies cumulatively evidence the scale's sound psychometric properties, and provide researchers with a previously unavailable scale, contributing towards enhancing the consistency of guanxi's measurement across future studies, and providing a deeper understanding of the phenomenon of guanxi.
\end{abstract}

Keywords: guanxi, scale development, scale validation, China

\section{Introduction}

Interpersonal relationships have been found to play a key role economic interactions both in Western and Chinese contexts (Burt, 1992; Luo, 2000; Xin \& Pearce, 1996), a role which has been found to be amplified within the Chinese context (Chen \& Chen, 2004; Luo et al., 2012; Chen et al., 2013). This increased influence can be attributed to the central role that guanxi plays in all facets of Chinese life. The term "guanxi" has been translated as "connections", "relations", or "relationships". However, such translations fail to capture the rich and dynamic phenomena which is guanxi (Chen et al., 2004). A phenomenon which widely acknowledge to impact on management outcomes in China and throughout the Asia-pacific region (Chou et al., 2014; Ahmed et al., 2014), hence guanxi been included as a focal construct in at least 180 business related studies to date (Chen et al., 2013)

Guanxi has been shown to be a distinctive from comparative constructs in other national contexts, (Smith et al., 2010). One particular point of divergence, is how guanxi influences labour market outcomes relative social networks in western contexts, where a wide spread of weak ties, has been shown to be more useful in gaining employment opportunities than strong ties (Bridges \& Villemez, 1986; Montgomery, 1992; Granovetter, 1973). However, the opposite relationship has been found in the Chinese labour market, where strong ties such as with immediate family members, associated with strong guanxi, are known to be more predictive of advantageous employment outcomes (Bian \& Ang, 1997; Bian, 1994). Thus, strong guanxi ties and networks act as social resources for job seekers (Hwang, 1987; Lin, 1982) which can be leveraged to obtain employment and career success (Bian, 1997; Xiao \& Tsui, 2007).

The reason for the greater influence of strong ties in the Chinese labour market context is attributed to the pivotal role of guanxi in Chinese society, coupled with the legacy of the centrally-controlled labour market of the planned economy era (Bian \& Huang, 2009; Walder, 1986). In this era, strong personal ties with an individual who could exert influence on the employer were required in order to receive beneficial from labour market outcomes. Consequently, information regarding employment opportunities received through weak ties was irrelevant for job seekers in this era (Bian, 1994; Bian, 1997). Post-labour market de-regulation, strong ties or strong guanxi were predicted to play a declining role in shaping employment outcomes (Guthrie, 1998; Guthrie, 
2002). However, research points to the sustained or even increasing impact of strong guanxi relationships in determining employment outcomes in China (Bian \& Huang, 2009).

Hence, key organisational outcomes can be presumed to be influenced by the strength of guanxi relationships with an organisation, which pre-date the commencement of the employment relationship. However although there have been calls from management scholars to development of new scales that are contextualised for the Chinese organisational environment (Tsui, 2006; Farh et al., 2006), to date the measurement of guanxi strength, particularly in at a pre-employment stage remains it its formative stages.

\subsection{The Measurement of Guanxi}

Guanxi to date it does not possess a widely applied means of measurement (Wong et al., 2010; Chen \& Chen, 2004; Yang, 2001b; Latham \& Gordon, 2009). The lack of a widely-accepted measure of guanxi can largely be attributed to the fact that it is a multidimensional, rich, complex, and dynamic construct (Yang, 2001a; Yang, 2001b; Chen et al., 2013). The multifaceted nature of guanxi is best demonstrated in the two differing broad conceptual approaches to the empirical investigation of guanxi, Chen and Chen (2004) define these approaches as 'categorical' or 'dynamic', samples of these approaches are provided in table 1. The categorical approach focuses on categories or particularistic relationships, such as family, when conceptualizing and measuring guanxi (Farh et al., 1998; Law et al., 2000b), whereas the dynamic approach places more emphasis on the general quality of guanxi relationships, revealed in their behavioral consequences, such as deferential behaviours, and/or affective dimensions such as trust which indicate the strength of guanxi present (Chen et al., 2009; Chen \& Peng, 2008; Law et al., 2000b).

Studies which take a categorical approach to guanxi measurement primarily utilize particularistic ties, such as family, classmates and acquaintances, as a means to gauge the presence and/or type of guanxi present (Tsang, 1998; Yeung \& Tung, 1996; Tsui \& Farh, 1997; Farh et al., 1998).Therefore, in studies adopting a categorical approach, the strength of guanxi is often inferred from the type of particularistic relationship with the guanxi-helper/person, and their proximity to the focal individual (Hwang, 1987; Zhang \& Zhang, 2006; Yang, 1993). The measurement of guanxi by relationship category is complicated by the fact that, although a particularistic relationship is a necessary precondition for guanxi, it does not guarantee its outcomes (Tsang, 1998). Hence, gauging guanxi purely by category of relationship provides only a partial measurement of the degree of guanxi present in a particular relationship (Kiong \& Kee, 1998; Hwang, 1987). Therefore, other researchers have elected to focus on the dynamic dimension of guanxi, measured by its behavioral and affective manifestations (Chen \& Peng, 2008; Cheung et al., 2008; Wong et al., 2003b). It should be recognized that capturing the interactions between the categorical and dynamic dimensions of guanxi in a single measure is complex, as highlighted by Latham and Gordon (2009) as in their study categorical and dynamic measures were found to produce divergent and even conflicting results.

In addition to the multidimensional nature of guanxi, the complexity of its measurement is further compounded by its sensitivity to context. This is illustrated by the fact that linguistically it is difficult to provide a concise definition of guanxi, as it is used as a loose term with multiple context-dependent meanings (Tsui \& Farh, 1997). The highly context-sensitive nature of guanxi can partially account for the lack of continuity in its measurement across studies as presented in table.1, of particular note to this study is that a majority of previous measures of guanxi, evaluate guanxi strength via post-employment behaviours (e.g., Chen \& Peng, 2008; Cheung et al., 2008; Wong et al., 2003b). Hence such measures are unsuitable for measuring guanxi which pre-dates the employment relationship. Thus, this paper, building on previous work, both categorical and dynamic, whilst also incorporating the context-dependent nature of guanxi, will develop and validate a new scale to measure guanxi which predates the employment relationship, specifically that of newly graduated job seekers in the Chinese labour market. 
Table 1. Previous guanxi measures

Source
Bian \& Ang (1997)
Farh, Tsui, Xin \& Cheng
(1998)

Law, Wong, Wang, \& Wang (2000)

Chen, Friedman, Yu, \& Sun (2011), adapted from Lin (2002)

Wong, Tinsley, Law, \& Mobley (2003a)

Chen, Chen, \& Xin (2004)

Chang \& Lii (2005)

Cheung \& Gui (2006)

Chen \& Peng (2008)

Cheung, $\mathrm{Wu}$, Chan \& Wong (2008), adapted from Liden, Wayne, \& Stilwell (1993)

Zhang, Soh, \& Wong (2009) Adapted from Burt \& Knez's (1995) and Bian's (1997)

Chen et al.,(2009)

Wong, Wong \& Wong (2010)

Measurement Approach
$\begin{aligned} & \text { Intimacy articularistic ties } \\ & \text { pand }\end{aligned}$

Sample Items

How well did you know the helper?

Connection to the helper:

kin to kin; kin to non-kin; non-kin to kin; non-kin to non-kin

Respondents were asked to indicate the presence of particularistic ties

Particularistic ties

Affective attachment

Differential behaviours

Classmate, relative; same family name; same province; former colleague; former teacher/student, former supervisor/subordinate; former neighbour

"I stand by my boss when there is any dispute."

"I give him/her gifts during festivals."

"Under the conditions of similar qualifications, my supervisor would assign me the important and easy-to-be-achieved job assignments."

"My supervisor allocates me more bonuses than others."

"I would lend him/her money"

Differential behaviours

"I would miss a work meeting in order to visit him/her in the hospital."

Differential behaviours and prevalence of guanxi networks.

Task allocations are often decided based on guanxi.

How likely it is that guanxi networks exist in your company?

"I would invite AAA's managers for family activities on

Perceived network holidays."

insider status

"I would invite AAA's managers to go abroad to participate in trade shows."

Intimacy and mutual Your closeness to the matchmaker.

familiarity

The matchmaker's familiarity with you.

Instrumental and expressive dimensions

Behavioural incidents positive and negative

Affective attachment

Duration, attachment affective frequency and

Affective attachment

"We can fully communicate about our feelings at work." "We trust each other."

The colleague kindly reminded you when he/she found the mistakes you made in your work.

The colleague did not return the money you loaned him.

"My supervisor understands my problems and needs."

"My supervisor invites me to his/her home for lunch/dinner."

How many years have you/they known each other prior to this resource acquisition?

To what extent do you agree that you then kept a close relationship with each other prior this resource acquisition?

To what extent do you agree that you/they met each other every week prior to this resource acquisition?

"After the office hour, I have social activities together with my supervisor such as having dinner together or having entertainment together which go beyond work duties."

"I am familiar with the family members of my supervisor and have personal contact with them"

"I have frequent interactions with my immediate

Frequency, mutual supervisor after work"

interest, and benefits
"I am quite willing to help my immediate supervisor after work (e.g., moving and decorating house)." 


\section{Scale Development and Validation Studies}

Developing and establishing the validity of a new scale is neither a onetime task, nor one which can be achieved using a singular approach (Schwab, 1980). Thus, the development and validation of the scale was undertaken over four studies, using a range of methodologies, as detailed in the following sections.

\subsection{Study One: Categorical Item Generation}

\subsubsection{Sample and Procedures}

Participants were recruited from business school graduates, in Study One, five separate Focus groups were conducted; Group One, $(n=10)$, Group Two, $(n=15)$, Group Three $(n=15)$, Group Four $(n=9)$, and Group Five $(\mathrm{n}=9)$, the mean age was 22.28 years $(\mathrm{SD}=.33)$, and $63 \%$ of the participants were female. Focus groups were used to generate the categorical items specifically by using a free-listing technique, which has often been used in anthropological studies to generate lists of terms associated with the domain of a specified construct (Walker \& Hennig, 2004; Brewer et al., 2002), also matching and basket sorting-type procedures were also used for categorizing the relationships, given the utility of these procedures in developing and accessing the content validity of scale items (Schriesheim et al., 1993; MacKenzie et al., 1991). The specific sorting technique used in the current study was pile-sorting, which is a method of domain analysis allowing the researcher to investigate how items relate to each other in the minds of research participants (Jenike et al., 2011; Bernard, 1994).

\subsubsection{Study One: Results}

From Group One's individual free-listing activity, 23 ways of categorizing or distinguishing guanxi relationships types were generated. In the subsequent group discussions which followed, overlapping terms were collapsed into single categories where possible. Here the relationship types of business partnership and customer-supplier were collapsed into "mutual-benefit", parents, grandparents and blood-brothers/sisters into "immediate family", and lastly school-mates, same home-town, and class-mates into "friend". The relationship type "good friend" was deleted as participants agreed; its common colloquial usage gave it an ambiguous meaning relative to the context of the study. A final list of eleven relationships categories was produced, which are presented in Table 2.

The results of the unconstrained individual pile-sorts of relationship categories were analyzed using cluster analysis, to derive sets of linkages between items (Johnson, 1967), identifying eight recurring criteria for classifying guanxi relationship types: (a) strong/close, moderate, weak/distant, (b) affection based or mutual benefit based (c) family, friendship and acquaintance/stranger. The constrained pile-sorts, sorted by guanxi strength, reveal that $100 \%$ of participants classified immediate family as representing strong/close guanxi, whilst $100 \%$ of participants classified those relationships which were neither friend nor family as weak/distant guanxi. For other relationships types, less definitive results were achieved. For example, 63\% of participants placed non-immediate family members in the strong/close guanxi category; however, $37 \%$ placed them in the moderate guanxi strength category. In subsequent discussions, participants indicated that when allocating a guanxi strength, with regard to eight of the eleven relationship types, their choice was dependent on a number of contextual variables. Consistent with the results of the first constrained pile-sort, the second constrained pile-sort revealed only one pair of relationship types as being definitively bi-polar, and thus suitable for anchors on a seven-point interval scale of '1' (Acquaintance) to '7' (Immediate family).

In Stage One of the de-brief, participants in Group Four and Group Five concluded that providing responses relative to five intervening points between the anchors of ' 1 ' (Acquaintance) and '7' (Immediate family) was highly arbitrary. Hence, participants concurred that inter-rater reliability would likely be weak for this type of interval scale item indicating guanxi strength in categorical type relationships. In addition, corroborating the findings of the preceding focus groups, participants also identified that interpretation of a number of the relationship types relative to guanxi strength was subjective, due to the highly contextualized personal nature of guanxi relationships, with the exception of immediate family relationships.

In Stage Two of the debriefing process, participants produced a number of hypothetical contextualized scenarios, introducing additional variables which would impact on the categories of relationship used to obtain an internship position at the host organization. Sample scenarios generated by participants are provided below:

"My father is a customs official; an acquaintance of my father's is a manager at this foreign trade firm".

"My old friend from my home-town is an employee at this company." 
Table 2. Study-one: Free-listing and constrained pile-sorting results

\begin{tabular}{|c|c|c|c|}
\hline Relationship Category & Weak Guanxi & Moderate Guanxi & Strong Guanxi \\
\hline Immediate Family & --- & --- & $100 \%$ \\
\hline Non-Immediate Family & --- & $37 \%$ & $63 \%$ \\
\hline Distant Family & $57 \%$ & $43 \%$ & --- \\
\hline Best Friend & --- & $83 \%$ & $17 \%$ \\
\hline Friend & $63 \%$ & $37 \%$ & --- \\
\hline Friend of friend & $78 \%$ & $22 \%$ & --- \\
\hline Friend of Immediate Family & $13 \%$ & $78 \%$ & --- \\
\hline Friend of Family & $64 \%$ & $36 \%$ & --- \\
\hline Mutual Benefit & $66 \%$ & $34 \%$ & --- \\
\hline Acquaintance & $100 \%$ & --- & --- \\
\hline Agent & $100 \%$ & --- & --- \\
\hline
\end{tabular}

Note: The English translations of relationship types are approximations, as Chinese vocabulary provides finer-grained distinctions between relationship types that are not available in English. Clarifications: Immediate Family (i.e. parents) Non-Immediate Family (i.e. 1st uncle), Distant Family (i.e. 2nd cousin).

The focus group discussion associated with such scenarios revealed that although in categorical terms the first scenario represents weaker guanxi according to Yang's (1993) classification its impact with regard to obtaining an internship position would be stronger even though the relationship was more distant in categorical terms. This highlights the problematic nature of using a stand-alone relationship category to measure guanxi's impact on outcomes, additionally. This finding also introduces the important dimension of the influence/power associated guanxi-helper relative to the employing organization, which shape the employment outcomes of a particular guanxi relationship.

\subsection{Study Two: Dynamic Item Generation}

\subsubsection{Sample and Procedures}

Table 3. Pilot pre-employment guanxi scale

\begin{tabular}{l}
\hline Item \\
GC-1. What was the type of relationship with the guanxi-person who helped you obtain this position? \\
Response Format: Immediate Family (S), Family (S), Distant Family (W), Best friend (M), Friend (W), Friend of \\
Friend (W), Friend of immediate family (M), friend of family (W), mutual benefit, acquaintance (W), agent(W) \\
GD-1. How important was guanxi in gaining the position? \\
Response Format: '1' (not important at all) to '7' (extremely important) \\
GD-2. How well did you know the guanxi-person prior to the internship? \\
Response Format: '1'(not at all) to '7' (very well) \\
GD-3. There was a strong relationship with the guanxi person. \\
Response Format: '1' (strongly disagree) to '7' (strongly agree) \\
GD-4. This guanxi person exerted substantial effort to assist me in obtaining my internship position. \\
Response Format: '1'(strongly disagree) to '7'(strongly agree) \\
GD-5. The guanxi person went significantly out of their way to assist me in obtaining this internship position. \\
Response Format: '1'(strongly disagree) to '7' (strongly agree) \\
GD-6. There was a high level of trust with the guanxi person. \\
Response Format: '1'(strongly disagree) to '7' (strongly agree) \\
GD-7. There was a close relationship between you and the guanxi person. \\
Response Format: '1' (strongly disagree) to '7' (strongly agree) \\
GI-1. The level of influence of the guanxi person's position was significant, factor in me obtaining this position. \\
Response Format: '1'(strongly disagree) to '7'(strongly agree) \\
GI-2. This guanxi person has significant influence relative to the internship organisation. \\
Response Format: 'I'(strongly disagree) to '7'(strongly agree)
\end{tabular}

Note: $(\mathrm{W})=$ weak guanxi, $(\mathrm{M})=$ moderate guanxi, $(\mathrm{S})=$ strong guanxi 
Study Two included three focus groups, new participants were recruited from the same sampling frame as Study One, although they who had not participated in the preceding focus groups. The sample size of the focus groups was: Group Six $(n=20)$, Group Seven $(n=20)$, and Group Eight $(n=16)$. The participants' mean age was 22.24 years $(\mathrm{sd}=.32)$, and $58 \%$ of the participants were female. Study two applied scenario method was used in the focus groups for the generation of the items associated with the dynamic dimensions of guanxi, similar to that previously used by Chen et al., (2004) for developing their guanxi scale, utilizing further free listing and pile sorting activities .

\subsubsection{Study Two: Results}

Three key variables emerged from the group free-lists and pile-sorts conducted in Study Two. Firstly, the degree of perceived bond with the guanxi-helper was regarded as a key determinant of the outcome of the scenarios provided. Participants concurred that this bond was best captured in the terms "strength" and "closeness". Secondly, the degree of "effort" exerted by the guanxi-helper, or alternatively the degree to which they "went out of their way", was also regarded as a behavioral indicator of the strength of guanxi present. Finally, the degree of the guanxi-helper's "influence", relative to the host organization, which could potentially be exerted on the intern's behalf, was also regarded as instrumental in determining the outcomes of the scenarios provided. Thus, two items relating to the guanxi-helper's influence relative to the host organization were also generated. Hence, the final pilot scale presented in table 3 consists of items capturing the categorical (GC), dynamic (GD), and influence (GI) dimensions of guanxi generated in studies One and Two in addition to two items adopted from Bian and Ang's (1997) study, given that their focal construct aimed to capture similar content as the PEG scale.

\subsection{Study Three: Pilot Scale, Validation}

\subsubsection{Sample and Procedures}

The sample for study three consisted of recent business school graduate. The pilot questionnaires were distributed to 352 graduates; from these, 227 valid questionnaires were returned, achieving a response rate of $70.04 \%$. Amongst the respondents, $54 \%$ of the sample were female, and the mean age of respondents was 22.74 years $(\mathrm{SD}=.40)$.

\subsubsection{Study Three: Results}

The Principles Component Analysis (PCA) results, presented in Table 4, indicated a two-factor structure cumulatively explaining $58.54 \%$ of the total variance. The items associated with GD loaded strongly onto the first factor, with the exception of item GD-5, loading weakly. Cross-loadings exceeding .30 were produced by items GC-1, GI-1, GI-2. This factor structure is consistent with extant theory and the results of Study One and Study Two. Firstly, as item GC-1 represents the categorical dimension of guanxi, which is a pre-requisite for the dynamic dimensions of guanxi, it can be expected to cross-load across dimensions. With regard to the cross-loadings produced by items GI-1 and GI-2, this is also consistent with the content of these items, as they both gauge the guanxi-helper's influence. The level of influence can be expected to be partially related to guanxi's dynamic dimension, as stronger guanxi would be required in order to receive a favour from a more powerful guanxi-helper.

Table 4. Principle components analysis pilot scale

\begin{tabular}{lll}
\hline Item & Factor-1 & Factor-2 \\
\hline GC-1 & .61 & .52 \\
GD-1 & .70 & --- \\
GD-2 & .57 & --- \\
GD-3 & .80 & --- \\
GD-4 & .71 & -- \\
GD-5 & .32 & --- \\
GD-6 & .82 & --- \\
GD-7 & .84 & --- \\
GI-1 & .64 & .60 \\
GI-2 & .72 & .44 \\
\hline
\end{tabular}

Note: Values $<.30$ suppressed 
Assessment of the sub-scales, internal reliability was conducted to corroborate the above PCA's results outlined in table 3. The GD sub-scale yielded an average coefficient alpha of $\alpha=.83$, and the GI subscale one of $\alpha=.83$. Consistent with their weak factor loadings, items GD-2 and GD-5 produced weak individual coefficient alphas at $\alpha=.47$ and $\alpha=.24$ respectively. Given the results of the PCA and internal reliability analysis, item GS-5 was deleted from the scale, whilst item GD-2 was singled out for greater scrutiny in subsequent CFA analysis.

The results of the CFA conducted on the six-item GD sub-scale are presented in Table 5, the scale yielded the following goodness-of-fit indices $(\chi 2=38.95, \mathrm{df}=9, \chi 2 / \mathrm{df}=4.32, \mathrm{TLI}=.92, \mathrm{CFI}=.95$, RMSEA $=.12$, SRMR $=.04$ ) indicating a poor degree of fit with the data. Additionally, relatively high modification indices were associated with items GD-1 GD-2, and GD-4, identifying these items as the source of the misspecification (Hildebrandt 1987; Steenkamp \& van Trijp 1991). Furthermore, these items achieved relatively weak factor loadings of GD-1 ( $\beta=.59)$, GD-2 ( $\beta=.48)$, and GD-4 ( $\beta=.64)$, indicating a lack of uni-dimensionality relative to the GS sub-scale.

Table 5. Confirmatory factor analysis dynamic guanxi sub scale

\begin{tabular}{ll}
\hline Item & Factor Loading \\
\hline GD-1 & .59 \\
GD-2 & .48 \\
GD-3 & .84 \\
GD-4 & .64 \\
GD-5 & --- \\
GD-6 & .84 \\
GD-7 & .85 \\
\hline
\end{tabular}

Both items GD-1 and GD-2, which produced problematic CFA results, were not newly developed for this study; rather they had been adapted from Bian and Ang's (1997) study. Therefore, unlike the new items developed in studies One and Two, the content validity of these items had not been previously been established in earlier focus groups, relative to the specific context of this research. The third item yielding poor results was item GD-4, which measures the 'effort' exerted by the guanxi-helper. Item GD-5, which also measures effort relative to the extent the guanxi-helper went 'out of their way' to help them acquire their internship position, was deleted subsequent to poor PCA results, as both of these last items require respondents to gauge events of which they potentially have no direct knowledge. Hence, gauging this dimension may be largely arbitrary. Given these results, a final refined six-item scale was produced from the cumulative results of studies One, Two and Three, includes items GC-1, GD-3, GD-6, GD-7, GI-1, and GI-2, a scale which achieved a better fit to the data.

\subsection{Study Four: Scale Test}

\subsubsection{Sample and Procedure}

Study Four was conducted in order to further establish appropriate dimensionality of the final scale, and to establish is discriminate validity of the scale by incorporating a selection of established scales into Study Four, namely Proactive Personality (Parker, 1998), Leader-Member Exchange (Liden et al., 1993), Learning Opportunities will be measured using (D'Abate et al., 2009), In-role Performance (Farh \& Cheng, 1999) and Job Satisfaction (Hackman \& Oldman, 1975). A total of 1019 surveys were distributed, of which 506 replied, amounting to a response rate of 49.7, 62.3 percent were female, and their mean age was 21.30 years.

\subsubsection{Study Four: Results}

The CFA performed on the measurement model including all latent variables simultaneously, yielded goodness-of-fit indices indicating that the measurement model's structure fits the data well $\left(\chi^{2}=633.10, \mathrm{df}=\right.$ $326, \chi 2 / \mathrm{df}=1.94, \mathrm{TLI}=.93, \mathrm{CFI}=.94, \mathrm{RMSEA}=.06, \mathrm{SRMR}=.05)$. Additionally, all items in the model achieved factor loadings in excess of .50 , indicating that items were measuring the appropriate latent variable (Steenkamp \& van Trijp, 1991), results which also support the appropriate dimensionality of the scale.

In regards to discriminant validity, the scale was firstly accessed by performing bivariate correlations between substantive latent variables, all correlations yielded were substantially below the recommended threshold of .70 indicting discriminant validity (Ping, 2004). Additional support for the presence of discriminant validity in this study is provided, with the testing of six models with alternative factor structures, contrasted with the baseline 
seven-factor measurement model used in the study. The results are presented in Table 6. All of the alternative models showed highly significant chi-square difference tests at $p<.001$, relative to the baseline model. This result supports the validity of the proposed seven-factor measurement model, and discriminant validity between the variables in the current study, as advised by Byrne (2010).

Table 6. Measurement model fit results for confirmatory factor analysis

\begin{tabular}{lllllllll}
\hline Models & $\chi^{2}$ & $\mathrm{df}$ & $\Delta \chi^{2}$ & $\Delta \mathrm{df}$ & TLI & CFI & RMSEA & SRMR \\
\hline Model 1 (7 factor) & 526.42 & 275 & $\overline{27}$ & $\overline{18}$ & .94 & .95 & .06 & .05 \\
Model 2 (6 factor) & 804.01 & 283 & 277 & .88 & .08 & .07 \\
Model 3 (5 factor) & 1402.36 & 289 & 875 & 14 & .73 & .76 & .13 & .18 \\
Model 4 (5 factor) & 1100.15 & 288 & 573 & 13 & .81 & .83 & .10 & .08 \\
Model 5 (3 factor) & 1338.54 & 295 & 812 & 20 & .76 & .78 & .12 & .08 \\
Model 6 (1 factor) & 3253.92 & 299 & 2727 & 24 & .32 & .37 & .19 & .18 \\
\hline
\end{tabular}

Notes: All $\Delta \chi 2$ difference tests were significant at $* * * \mathrm{p}<.001$

All models contrasted with Model-6.

As a final check of discriminant validity of the scale, nested chi-squared difference tests were performed between pairings of all the study's latent variables, constrained then un-constrained, as recommended by Bryne (2010). These tests produced significant chi-square differences at $\mathrm{p}=<.001$ level, thus providing further evidence of discriminant validity of the PEG scale (Anderson \& Gerbing, 1988; Byrne, 2010).

\section{Discussion}

\subsection{Theoretical Implications}

This paper developed and validated a new scale measuring PEG, over four studies. With regard to the categorical items generated for the scale via the free-listing and pile-sorting techniques, the categories generated largely aligned with the relationship categories of Family, Friend, and Acquaintance, proposed in previous work (e.g., Luo, 1997; Yang, 1994; Farh et al., 1998). Additionally, the clusters which emerged using strength/closeness, affection, and mutual benefit as grouping criteria are also supported in the existing literature (Tsang, 1998; Tsui \& Farh, 1997). However, the findings diverged from previous categorically guanxi work, in that only three of the eleven relationship types could not be definitively aligned with guanxi strength, whereas previous work suggests relatively clear linkages between guanxi strength and categorical relationship proximity to the focal individual (Luo, 1997; Yang, 1997).

Specifically, previous categorical work aligned non-immediate family (i.e. first uncle) relationship categories with strong guanxi, as they were based on unconditional obligations, distinguished from weaker, more flexible forms of guanxi, including friendship (Hwang, 1987; Yang, 1993; Zhang \& Zhang, 2006), whereas in this study this relationship category did not definitively align with strong guanxi, as asserted in previous work. This lack of clear guanxi strength demarcation between relationship categories may be attributed to the specific characteristics of the sample and target population, as they belong to a relatively homogenous generational cohort, which has been shown to hold less traditional values than the preceding generations of Chinese employees (McEwen et al., 2006; Gu et al., 2010). Hence, it is plausible that the traditionally-prescribed demarcation between relationship categories and associated guanxi strength is less rigidly defined amongst the next generation of Chinese employees.

Participants in studies One and Two identified the problematic nature of linking relationship categories with tangible outcomes of guanxi, consistent with Chen and Peng's (2008) distinction of guanxi practices from guanxi relational bases. Specifically, participants in this study emphasised the importance of the dynamic dimension of guanxi for gauging the actual strength of guanxi present. For instance, participants highlighted the degree of effort exerted by the guanxi-helper, on the respondent's behalf, as indicative of the strength of guanxi present. These sentiments echo that of Lin's (1999) network-ties research findings within Western contexts, which associate effort with the strength of a network tie. Additionally, a contextual variable of particular importance emerged in this study; the influence/power associated with the guanxi-helper relative to the host organisation. This finding converges with previous studies, suggesting that the influence/power associated with the guanxi was key in determining employment outcomes in China (Bian, 1997; Cheung \& Gui, 2006; Bian \& Ang, 1997). 


\subsection{Methodological Implications}

In addition to the numerous theoretical contributions, this study is also able to contribute to methodological advancement, as it both developed and validated a new scale measuring pre-internship guanxi. Firstly, this study provides guidance to organisational researchers who wish to develop contextually relevant scales. This is because a number of the techniques used to generate items in the study were borrowed from anthropological researchers, including free-listing, pile-sorting, and scenario activities, are not commonly used in organisational research, therefore this study was able to demonstrate their utility for unearthing specific contextual elements when generating items for inclusion in scales used in organisational studies.

In addition, the study provides a measure of pre-internship guanxi for use in future studies. Hence, this study contributes towards answering calls from prominent Chinese management scholars for the development of new scales that are contextualised for the Chinese organisational environment (Tsui, 2006; Farh et al., 2006). Specifically this study develops and validates a means to measure a specific manifestation of the variable of guanxi, an indigenous variable which is acknowledged to have far-reaching impacts on Chinese organisational phenomena (Cheung et al., 2009; Smith et al., 2010; Hwang, 2004; Wong \& Wong, 2013). Provision of this measure makes a notable contribution as despite guanxi been included as a focal construct in at least 235 organisational studies over the last three decades (Chen et al., 2013) researchers have noted that a well-defined coherent operationalization and consequently measurement of guanxi remains in its formative stages (Wong et al., 2010; Chen et al., 2004).

\subsection{Implications for Management Practice}

The impact of both guanxi's categorical and dynamic dimensions on management practice in China has long been acknowledged. This study suggests that managers should place a heaver emphasis on the dynamic dimensions of guanxi, when considering relationships in the workplace, particularly when approaching relationships with the younger generation of Chinese employees, as this study indicates that this generations conceptualisation of guanxi has evolved away from its categorical roots, blurring traditional demarcations between guanxi relationship categories (King, 1991; Jacobs, 1982; Tsang, 1998). Thus managers should be increasingly aware of the dynamic and fluid nature of guanxi, when approaching cross generational issues in the Chinese context (Cheung et al., 2008; Chen \& Peng, 2008). Furthermore, these findings highlight to managers, that the next generation of Chinese employees bring a unique sets of attitudes, motivations to the workplace relative to preceding generations of Chinese employees, which will increasingly shape future management practices in China (McEwen et al., 2006; Gu et al., 2010), and guanxi's impact in the workplace.

\subsection{Limitations and Future Studies}

As aforementioned developing and establishing the validity of a new scale is an ongoing process. Thus, the scale developed in this study can be regarded as a preliminarily scale requiring further validation. Therefore, future studies are encouraged to test the scale on broader sample populations, outside of graduate job seekers, in addition to establishing both the divergent and convergent validity of the scale relative to additional relevant constructs.

\section{Acknowledgements}

This paper has been supported by the 2014 Hannam University Research Fund.

\section{References}

Ahmed, I., Ismail, W. K. W., \& Amin, S. M. (2014). Guanxi network and leader member exchange: The impetus for employee creative involvement. Asia-Pacific Journal of Business Administration, 6, 64-77. http://dx.doi.org/10.1108/APJBA-05-2013-0048

Anderson, J. C., \& Gerbing, D. W. (1988). Structural Equation Modeling in Practice: A Review and Recommended Two-Step Approach. Psychological Bulletin, 103, 411-423. http://dx.doi.org/10.1037/0033 $-2909.103 .3 .411$

Bernard, H. R. (1994). Research Methods in Anthropology: Qualitative and Quantitative Approaches. Walnut Creek, Altimira.

Bian, Y. (1994). Guanxi and the Allocation of Urban Jobs in China. The China Quarterly, 140, 971-999. http://dx.doi.org/10.1017/S0305741000052863

Bian, Y. (1997). Bringing strong ties back in: Indirect ties, network bridges, and job searches in China. American Sociological Review, 62, 269-286. http://dx.doi.org/10.2307/2657311 
Bian, Y., \& Ang, S. (1997). Guanxi networks and job mobility in China and Singapore. Social Forces, 75, 981-1005. http://dx.doi.org/10.1093/sf/75.3.981

Bian, Y., \& Huang, X. (2009). Network resources and job mobility in China's transitional economy. In L. Keister (Ed.), Work and organizations in China after thirty years of transition research in the sociology of work. Bingley: Emerald Group Publishing. http://dx.doi.org/10.1108/S0277-2833(2009)0000019012

Brewer, D. D., Garrett, S. B., \& Rinaldi, G. (2002). Free-listed items are effective cues for eliciting additional items in semantic domains. Applied Cognitive Psychology, 16, 343-358. http://dx.doi.org/10.1002/acp.797

Bridges, C., \& Villemez, W. (1986). Informal hiring and income in labor market. American Sociological Review, 62, 574-582. http://dx.doi.org/10.2307/2095589

Burt, R. S. (1992). Structural holes: The social structure of competition. Cambridge, MA, Harvard University Press.

Burt, R. S., \& Knez, M. (1995). Kinds of third-party effects on trust. Rationality and Society. Rationality and Society, 7, 255-292. http://dx.doi.org/10.1177/1043463195007003003

Byrne, B. M. (2010). Structural Equation Modeling with AMOS: Basic Concepts, Applications, and Programming. New York: Routledge.

Chang, W. L., \& Lii, P. (2005). The impact of guanxi on Chinese managers transactional decisions: A study of Taiwanese SMEs. Human Systems Management, 24, 215-222.

Chen, C. C., Chen, X. P., \& Huang, S. (2013). Chinese Guanxi: An Integrative Review and New Directions for Future Research. Management and Organization Review, 9, 167-207. http://dx.doi.org/10.1111/more.12010

Chen, C. C., Chen, Y. R., \& Xin, K. (2004). Guanxi practices and trust in management: A procedural justice perspective. Organisational Science, 15, 200-209. http://dx.doi.org/10.1287/orsc.1030.0047

Chen, X. P., \& Chen, C. C. (2004). On the intricacies of the Chinese guanxi: A process model of guanxi development. Asia Pacific Journal of Management, 21, 305-324. http://dx.doi.org/10.1023/B:APJM.00000 36465.19102.d5

Chen, X. P., \& Peng, S. (2008). Guanxi Dynamics: Shifts in the closeness of ties between Chinese coworkers. Management and Organization Review, 4, 63-80. http://dx.doi.org/10.1111/j.1740-8784.2007.00078.x

Chen, Y., Friedman, R., Enhai, Y., Fang, W., \& Lu, X. (2009). Supervisor-Subordinate Guanxi: Developing a Three-Dimensional Model and Scale. Management and Organization Review, 5, 375-399. http://dx.doi.org/ 10.1111/j.1740-8784.2009.00153.x

Chen, Y., Friedman, R., Yu, E., \& Sun, F. (2011). Examining the positive and negative effects of guanxi practices: A multi-level analysis of guanxi practices and procedural justice perceptions. Asia Pacific Journal of Management, 28, 715-736. http://dx.doi.org/10.1007/s10490-009-9176-x

Cheung, C. K., \& Gui, Y. (2006). Job referral in China: The advantages of strong ties. Human Relations, 59, 847-872. http://dx.doi.org/10.1177/0018726706067151

Cheung, F. Y., Wu, W. P., Chan, K. K., \& Wong, M. L. (2009). Supervisor-subordinate guanxi and employee work outcomes: The mediating role of job satisfaction. Journal of Business Ethics, 88, 77-89. http://dx.doi. org/10.1007/s10551-008-9830-0

Cheung, M. F. Y., Wu, W. P., Chan, A. K. K., \& Wong, M. M. L. (2008). Supervisor-Subordinate Guanxi and Employee Work Outcomes: The Mediating Role of Job Satisfaction. Journal of Business Ethics, 88, 77-89. http://dx.doi.org/10.1007/s10551-008-9830-0

Chou, S. Y., Han, B., \& Zhang, X. (2014). Effect of guanxi on Chinese subordinates' work behaviors: A conceptual framework. Asia-Pacific Journal of Business Administration, 6, 8-35.

D'abate, C. P., Youndt, M. A., \& Wenzel, K. E. (2009). Making the most of an internship: An empirical study of internship satisfaction. Academy of Management Learning \& Education, 8, 527-539. http://dx.doi.org/10. 5465/AMLE.2009.47785471

Farh, J. L., \& Cheng, B. S. (1999). An investigation of modesty bias in self-ratings of work performance among Taiwan workers. Chinese Journal of Psychology, 39, 103-118.

Farh, J. L., Cannella, A., \& Lee, C. (2006). Approaches to Scale Development in Chinese Management Research. Management and Organization Review, 2, 301-318. http://dx.doi.org/10.1111/j.1740-8784.2006.00055.x 
Farh, J. L., Tsui, A. S., Xin, K. R., \& Cheng, B. S. (1998). The influence of relational-demography and guanxi: The Chinese case. Organization Science, 9, 471-488. http://dx.doi.org/10.1287/orsc.9.4.471

Granovetter, M. (1973). The strength of weak ties. American Journal of Sociology, 78, 1360-1380. http://dx.doi. org/10.1086/225469

Gu, Q., Wang, L., Sun, J. Y., \& Xu, Y. (2010). Understanding China's Post-80s employees work attitudes: An explorative study. Journal of Chinese Human Resource Management, 1, 74-94. http://dx.doi.org/10.1108/ 20408001011117635

Guthrie, D. (1998). The declining significance of Guanxi in China's economic transition. The China Quarterly, 154, 254-282. http://dx.doi.org/10.1017/S0305741000002034

Guthrie, D. (2002). Information asymmetries and the problem of perception: The significance of structural position in accessing the importance of Guanxi in China. In T. Gold, D. Guthrie, \& D. Wank (Eds.), Social connections in China: Institutions, culture, and the changing nature of Guanxi. New York: Cambridge University Press. http://dx.doi.org/10.1017/CBO9780511499579.004

Hackman, R., \& Oldman, G. R. (1975). Development of the Job Diagnostic Survey. Journal of Applied Psychology, 60, 159-170. http://dx.doi.org/10.1037/h0076546

Hwang, K. K. (1987). Face and favor: The Chinese power game. American Journal of Sociology, 92, 944-974. http://dx.doi.org/10.1086/228588

Hwang, K. K. (2004). Social connections in China: Institutions, culture, and the changing nature of guanxi. Contemporary Sociology: A Journal of Reviews, 33, 572-573. http://dx.doi.org/10.1177/0094306104033 00539

Jacobs, J. B. (Ed.). (1982). The concept of guanxi and local politics in rural Chinese cultural setting. New York: Praeger Publisher.

Jenike, M. R., Lutz, K., Vaaler, C., Szabo, S., \& Mielke, J. E. (2011). Thinking about food drink, and nutrition amoung ninth graders in the United States Midwest: A case study of local partnership research. Human Organization, 70, 139-152.

Johnson, S. C. (1967). Hierarchical clustering schemes. Psychometric, 32, 241-254. http://dx.doi.org/10.1007/BF 02289588

King, A. Y. (1991). Kuan-hsi and network building: A sociological interpretation. Daedalus, 120, 63-84.

Kiong, T. C., \& Kee, Y. P. (1998). Guanxi bases, xinyong and Chinese business networks. British Journal of Sociology, 49, 75-96. http://dx.doi.org/10.2307/591264

Latham, G., \& Gordon, R. (2009). Beware of different guanxi measurements when doing research in China. The 23rd Annual Conference of Australia New Zealand Academy of Management (ANZAM): Sustainable Management and Marketing. Melbourne, Australia: Australia New Zealand Academy of Management (ANZAM).

Law, K. S., Wong, C. S., Wang, D., \& Wang, L. (2000). Effect of supervisor-subordinate guanxi on supervisory decisions in China: An empirical investigation. International Journal of Human Resource Management, 11, 751-765. http://dx.doi.org/10.1080/09585190050075105

Liden, R. C., Wayne, S. J., \& Stilwell, D. (1993). A longitudinal study on the early development of leader-member exchanges. Journal of Applied Psychology, 78, 662-674. http://dx.doi.org/10.1037/00219010.78.4.662

Lin, M. (2002). The effects of supervisors' chaxugejv on leadership behaviors and effectiveness. Masters unpublished, National Zhongshan University.

Lin, N. (1982). Social resources and instrumental action. In P. V. Marsden, \& N. Lin (Eds.), Social structure and network analysis. Beverly Hills, CA: Sage.

Lin, N. (1999). Social networks and status attainment. Annual Review of Sociology, 25, 467-487. http://dx.doi. org/10.1146/annurev.soc.25.1.467

Luo, Y. (1997). Guanxi: Principles, philosophies, and implications. Human Systems Management, 16, 43-51.

Luo, Y. D. (2000). Guanxi and Business, River Edge. New Jersey, World Scientific. http://dx.doi.org/10.1142/ 4258 
Luo, Y., Huang, Y., \& Wang, S. L. (2012). Guanxi and organisational performance: A meta-analysis. Management and Organisation Review, 8, 139-172. http://dx.doi.org/10.1111/j.1740-8784.2011.00273.x

Mackenzie, S. B., Podsakoff, N. P., \& Fetter, R. (1991). Organizational citizenship behavior and objective productivity as determinants of managerial evaluations of salespersons' performance. Organizational Behavior and Human Decision Processes, 50, 123-150. http://dx.doi.org/10.1016/0749-5978(91)90037-T

Mcewen, W., Fang, X., \& Zhang, C. (2006). Inside the mind of the Chinese consumer. Harvard Business Review, $3,1-10$.

Montgomery, J. (1992). Job search and network composition: Implications of the strength-of-weak-ties hypothesis. American Sociological Review, 51, 586-596. http://dx.doi.org/10.2307/2095914

Parker, S. K. (1998). Enhancing role breadth self-efficacy: The roles of job enrichment and other organisational interventions. Journal of Applied Psychology, 83, 835-852. http://dx.doi.org/10.1037/0021-9010.83.6.835

Ping, R. A. Jr. (2004). On Assuring Valid Measures for Theoretical Models Using Survey Data. Journal of Business Research, 57, 125-141. http://dx.doi.org/10.1016/S0148-2963(01)00297-1

Schriesheim, C. A., Powers, K. J., Scandura, T. A., Gardiner, C. C., \& Lankau, M. J. (1993). Improving construct measurement in management research: Comments and a quantitative approach for assessing the theoretical content adequacy of paper-and-pencil survey-type instruments. The Journal of Management, 19, 385-417. http://dx.doi.org/10.1016/0149-2063(93)90058-U

Schwab, D. P. (1980). Construct validity in organizational behavior. In L. L. Cummings, \& B. M. Staw (Eds.), Research in Organisational Behavior. Greenwich, C.T: JAI press.

Smith, P. B., Huang, H. J., Harb, C., \& Torres, C. (2010). How distinctive are indigenous ways of achieving influence? A comparative study of guanxi, wasta, jeitinho and "pulling strings". Journal of Cross-Cultural Psychology, 20, 1-16.

Tsang, E. W. K. (1998). Can guanxi be a source of sustained competitive advantage for doing business in China? Academy of Management Executive, 12, 64-73. http://dx.doi.org/10.5465/AME.1998.650517

Tsui, A. S. (2006). Contextualization in Chinese Management Research. Management and Organization Review, 2, 1-13. http://dx.doi.org/10.1111/j.1740-8784.2006.00033.x

Tsui, A. S., \& Farh, J. H. (1997). Where guanxi matters: relational demography and Guanxi in the Chinese context. Work and Occupations, 24, 56-79. http://dx.doi.org/10.1177/0730888497024001005

Walder, A. G. (1986). Communist neo-traditionalism: Work and authority in Chinese industry. Berkeley, University California Press.

Walker, L. J., \& Hennig, K. H. (2004). Differing conceptions of moral exemplarity: Just, brave, and caring. Journal of Personality and Social Psychology, 86, 629-647. http://dx.doi.org/10.1037/0022-3514.86.4.629

Wong, C. S., Tinsley, C., Law, K. S., \& Mobley, W. H. (2003). Development and validation of multidimensional measure of guanxi. Journal of Psychology in Chinese Societies, 4, 43-69.

Wong, Y. T., \& Wong, Y. W. (2013). Workplace guanxi and employee commitment to supervisor in Chinese joint ventures. Journal of Chinese Human Resource Management, 4, 1-31. http://dx.doi.org/10.1108/JCHRM-012013-0003

Wong, Y. T., Ng, H. Y., \& Wong, C. S. (2003). Antecedents and outcomes of employees' trust in Chinese joint ventures. Asia Pacific Journal of Management, 20, 481-499. http://dx.doi.org/10.1023/A:1026391009543

Wong, Y. T., Wong, S. H., \& Wong, Y. W. (2010). A study of subordinate-supervisor guanxi in Chinese joint ventures. International Journal of Human Resource Management, 21, 2142-2155. http://dx.doi.org/10.1080/ 09585192.2010 .509621

Xiao, Z., \& Tsui, A. S. (2007). When brokers may not work: The cultural contingency of social capital in Chinese high-tech firms. Administrative Science Quarterly, 52, 1-31.

Xin, K. R., \& Pearce, J. L. (1996). Guanxi: Connections as substitute for formal institutional support. Academy of Management Journal, 39, 1641-1658. http://dx.doi.org/10.2307/257072

Yang, C. F. (Ed.). (1997). Psycho-cultural foundations of informal group: The issues of loyalty, sincerity, and trust. New York: Cambridge University Press.

Yang, C. F. (Ed.). (2001a). A critical review of the conceptualization of guanxi and renqing. In C. F. Yang (Ed.), 
The interpersonal relationship, affection, and trust of the Chinese: From an interactional perspective. Taipei: Yuan Liou Publishing Co.

Yang, C. F. (Ed.). (2001b). A reconceptualization of the Chinese guanxi and renqing. Taipei: Yuan Liou Publishing Co.

Yang, K. S. (Ed.). (1993). Chinese social orientation: A social dynamic perspective. Taipei: Kui Kwan Publishing.

Yang, M. M. (1994). Gifts, Favors and Banquets: The Art of Social Relationships in China. Ithaca, MY, Cornell University Press.

Yeung, I. Y. M., \& Tung, R. L. (1996). Achieving success in Confucian societies: The importance of guanxi (connections). Organizational Dynamics, 25, 54-65. http://dx.doi.org/10.1016/S0090-2616(96)90025-X

Zhang, Y., \& Zhang, Z. (2006). Guanxi and organizational dynamics in China: a link between individual and organizational levels. Journal of Business Ethics, 375-392. http://dx.doi.org/10.1007/s10551-006-9031-7

Zhang, Z., Soh, P. H., \& Wong, P. K. (2009). Entrepreneurial Resource Acquisition through Indirect Ties: Compensatory Effects of Prior Knowledge. Journal of Management, 36, 511-536. http://dx.doi.org/10.1177/ 0149206308329963

\section{Copyrights}

Copyright for this article is retained by the author(s), with first publication rights granted to the journal.

This is an open-access article distributed under the terms and conditions of the Creative Commons Attribution license (http://creativecommons.org/licenses/by/3.0/). 